\title{
A focused approach: Specialization in coronary revascularization
}

\author{
William Z. Chancellor, MD, and Irving L. Kron, MD \\ From the Division of Thoracic and Cardiovascular Surgery, Department of Surgery, University of Virginia, Char- \\ lottesville, Va. \\ Disclosures: Authors have nothing to disclose with regard to commercial support. \\ Received for publication Sept 4, 2018; accepted for publication Sept 4, 2018; available ahead of print Oct 17, \\ 2018. \\ Address for reprints: Irving L. Kron, MD, Division of Thoracic and Cardiovascular Surgery, Department of Sur- \\ gery, University of Virginia, PO Box 800679, Charlottesville, VA 22908 (E-mail: ilk@ virginia.edu). \\ J Thorac Cardiovasc Surg 2019;157:948-9 \\ 0022-5223/\$0.00 \\ Published by Elsevier Inc. on behalf of The American Association for Thoracic Surgery \\ https://doi.org/10.1016/j.jtcvs.2018.09.004
}

Because of the rapid expansion of medical knowledge and the growing number of procedures at our disposal, further subspecialization is inevitable in cardiac surgery. We have already seen evidence that specialization leads to increased guideline adherence and better outcomes in relatively rare circumstances such as mitral valve surgery. ${ }^{1}$ In this edition of the Journal, Mack and Taggart ${ }^{2}$ argue that even an operation as common as coronary artery bypass grafting (CABG) can benefit from the focused attention and expertise that comes with subspecialization.

At 50 years old, CABG is still the most commonly performed cardiac surgery procedure, accounting for $54 \%$ of operations in the most recent Society of Thoracic Surgeons report. ${ }^{3}$ Indeed, reports of the death of CABG have been greatly exaggerated. Despite laudable advances in medical therapy and stent technology, CABG remains the criterion standard for coronary revascularization, particularly for patients with complex multivessel coronary disease or patients with diabetes. There is no doubt that CABG is a lifesaving and definitive procedure when performed by a qualified surgeon. ${ }^{4}$ More subjectively, we have found that coronary surgery is among the most difficult of cardiac operations to teach and to perform consistently at a high level.

With all this in mind, it is clear why Mack and Taggart ${ }^{2}$ wish to highlight the importance of coronary surgery, not just as the backbone of our profession but also as its own subspecialty. An operation that affects more than 150,000 patients per year deserves that level of focused attention and expert oversight. Specifically, their proposals to identify a network of experienced professionals to serve as thought leaders and to implement a heart team approach to coronary revascularization are overdue. The implication is that a multidisciplinary team dedicated to revascularization would ensure guideline adherence and future innovation. Currently, such evidence-based practices as off-pump $\mathrm{CABG}$ and bilateral internal thoracic artery conduits are

\section{References}

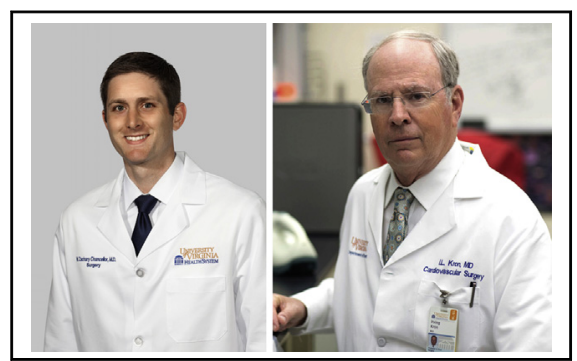

William Z. Chancellor, MD (left), and Irving L. Kron, $\mathrm{MD}$ (right)

Central Message

Although subspecialization is inevitable in modern medicine, it is important that all cardiac surgeons be empowered and enabled to perform coronary artery bypass grafting at the highest level.

See Article page 945

underused, and any mechanism that could ensure more widespread implementation is worthwhile. Furthermore, surgeons dedicated to coronary revascularization would be in a unique position to continue researching optimal conduits, cardiac protection, perioperative care, and minimally invasive techniques, which will be essential to the continued success of CABG going forward.

It is reasonable to assume that surgeons seeking to be designated as coronary revascularization specialists would be concentrated at academic centers, at least initially. It is imperative to ensure that they stay there. To be most effective, those who are passionate about optimizing CABG outcomes should also be committed to instilling that passion in trainees. In all likelihood, most CABG operations will continue to be performed by so-called generalist cardiac surgeons. Establishing a subspecialty focus in coronary surgery will not take away from all surgeons performing CABG. Rather, it will provide an educational and research focus that will make the procedure better.

1. Chikwe J, Toyoda N, Anyanwu AC, Itagaki S, Egorova NN, Boateng P, et al. Relation of mitral valve surgery volume to repair rate, durability, and survival. J Am Coll Cardiol. 2017;69:2397-406.

2. Mack M, Taggart D. Coronary revascularization should be a subspecialty focus in cardiac surgery. J Thorac Cardiovasc Surg. 2019;157:945-7. 
3. D'Agostino RS, Jacobs JP, Badhwar V, Fernandez FG, Paone G, Wormuth DW, et al. The Society of Thoracic Surgeons adult cardiac surgery database: 2018 update on outcomes and quality. Ann Thorac Surg. 2018;105: $15-23$.
4. Head SJ, Milojevic M, Daeman J, Ahn JM, Boersma E, Christiansen EH, et al Mortality after coronary artery bypass grafting versus percutaneous coronary intervention with stenting for coronary artery disease: a pooled analysis of individual patient data. Lancet. 2018;391:939-48. Erratum in: Lancet. 2018;392:476. 